\title{
A Self-similarity Traffic Analysis of an Internet-based Multiplayer Online Game
}

\author{
John C. McEachen II \\ Naval Postgraduate School, 833 Dyer Road, Code EC/Mj, Monterey, California 93943 \\ mceachen@nps.edu
}

\begin{abstract}
An analysis of traffic generated by the popular Internet-based online game engine, Unreal Engine, is presented. Network parameters such as packet length, interarrival time and aggregate data rate are observed for analyzing aspects of self-similarity. Client-side packet traces are collected and analyzed for both client and server traffic. Initial analysis of over three million packets indicates client generated traffic shows strong long-range dependence of a self-similar nature primarily due to packet length associated with user actions. On the contrary, server generated traffic seen at the client, while still exhibiting a heavy tail, is more short-range dependent in regions where self-similarity is observed.
\end{abstract}

\section{Categories and Subject Descriptors}

C.4 [Performance of Systems]: Measurement techniques, Performance attributes

General Terms - Measurement, Performance.

Keywords - Self-similarity, multiplayer, MMOG.

\section{INTRODUCTION}

In this paper, one of the more popular Internet-based online games, America's Army: Operations (AAO) is analyzed [1]. AAO is a first person shooter (FPS) loose MMOG developed for the U.S. Department of the Army by the U.S. Naval Postgraduate School. AAO is part of a new class of games referred to as "advergames" - the U.S. Army gives the game away for free for recruitment purposes and to foster increased understanding of Army operations [2]. As of April, 2003, AAO had 1.3 million registered users, $27 \%$ of which were believed to be outside the United States.

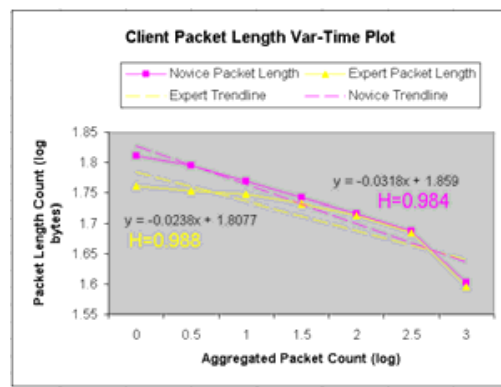

Figure 1. (Above) Variance-Time series plot for length of packets generated by the client. Plots for an "expert" user and a novice are shown. (Top right) Variance-time series plot of interarrival time between packets generated by the client. (Bottom right) Variance-time series plot for the cumulative data rate at differing time scales.

Copyright is held by the author/owner(s)

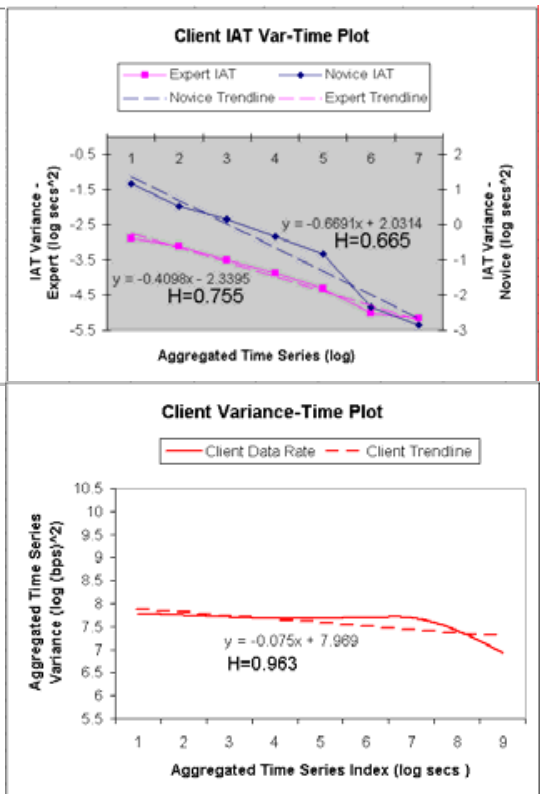

SIGCOMM'04 Workshops, Aug. 30 \& Sept. 3, 2004, Portland, OR, USA.

ACM 1-58113-942-X/04/0008.
The traffic characteristics of AAO are examined exclusively. The effect of WAN transport networks on IP traffic has been extensively discussed (e.g. [3]). Consequently, it would be reasonable to assume that the characteristics of WAN-based MMOGs would be different than those seen in the LAN environment. This paper specifically looks at traces observed from the position of the client because it was assumed that this would be the location most likely to observe the cumulative effect of WAN-based variations on the traffic of interest.

\section{SELF-SIMILARITY ANALYSIS}

A common technique for estimating the degree of self-similarity in a packet trace is by examining the variance of the distribution for different order time series. As discussed in [4], the Hurst parameter, $H$, is frequently used as a measure of self-similarity in a random process. $H$ is proportional to the negative slope of time series plot. Figures 1 and 2 illustrate the variance-time series plots for both client and server generated packets for packet length, interarrival time, and aggregate data rate.

\section{REFERENCES}

[1] http://www.americasarmy.com/

[2] Wiltenburg, M., "More than playing games," Reuters/Christian Science Monitor, April 3, 2003.

[3] Floyd, S. and Paxson, V., "Difficulties in simulating the Internet," IEEE/ACM Trans. on Networking, vol. 9, no. 4, August 2001. pp. 392 - 403.

[4] Leland, W. E., Taqqu, M.S., Willinger, W., Wilson, D.V., "On the self-similar nature of Ethernet traffic (extended version),” IEEE/ACM Trans. on Networking, vol. 2,no. 1, Feb 1994. pp. $1-15$.

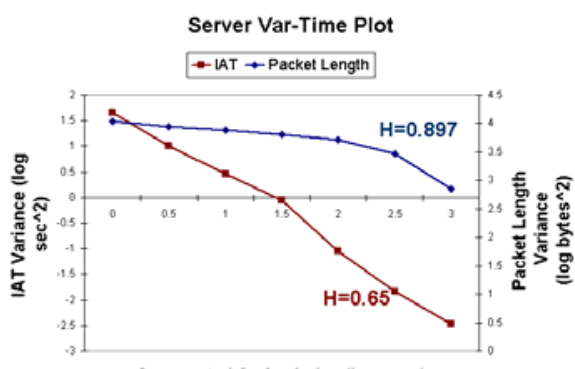

Aggregated Series Index (log secs)

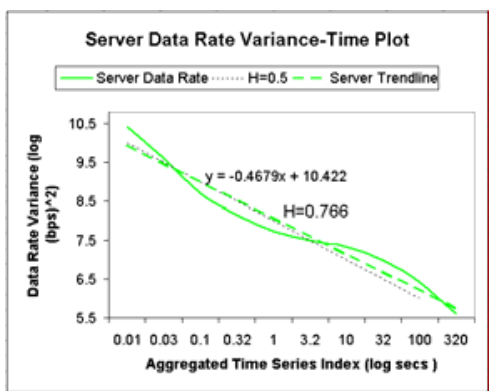

Figure 2. (Top) Variance-Time series plot for length of packets and interarrival time between packets generated by the client. (Bottom) Variance-time series plot for the cumulative data rate at differing time scales. 